\title{
Influence of technological system's rigidity on the dynamics of grinding process of flexible parts
}

\author{
Sergey A. Voronov*, Igor A. Kiselev, and Weidong Ma \\ Bauman Moscow State Technical University, 105005 Moscow, Russia
}

\begin{abstract}
The object of the present study is to investigate the dynamic of plane grinding by the tool with random distribution of abrasive grains, owning random geometric characteristics. The model is based on the consideration of machining system's dynamical deformable characteristics, which have influence on the workpiece's displacement under grinding process. The excitation of vibrations has significant effects on precision and surface quality, which is especially important in machining spatial parts, such as turbine blades.
\end{abstract}

\section{Introduction}

During grinding processing for parts with low stiffness, such as turbine blades, in some cases, self-oscillations arise, which will lead to inaccuracy of shape and loss of surface quality. In addition, there occur elastic deflections due to the cutting forces, besides residual stresses, which will lead to part warping and loss of operational characteristics. Therefore, the accuracy and quality of the treated surface, the character of system's dynamical behaviour should be studied in details, which are depending on the fixings stiffness, the geometry of part and tool, cutting conditions.

\section{Simplified model of flat grinding}

While modelling, it's possible to consider the abrasive grain as an elementary cutting edge interacting with the workpiece material [1-4]. Introduce a model of flat grinding, which is presented in paper [5], assuming that: (1) Abrasive grains are evenly distributed over the wheel surface. Grains are evenly distributed across the width of the wheel by several tracks (see Fig. 1), in order to describe the system movement by the differential equations with a constant time delay $T / N$ ( $T$-the period of wheel rotation, $N$-the number of grains on one track); (2) All the grains have random geometric characteristics (grain's height $h_{0}$, the cone angle $\theta$, the yaw angle $\alpha$ ).

To simulate the grinding process with consideration of part's compliance, the grinding process of parts with low stiffness is modelled as a flat system with two orthogonal degrees of freedom, as shown in Fig. 1, where $m$ - mass of the part. $C_{x}, C_{z}$ - coefficient of damping

* Corresponding author: voronovsa@yahoo.com 
factors for part's bindings, $K_{x}, K_{z}$ - coefficient of stiffness for part in the direction of $X$ and $Z$ axes, reduced to the contact point.
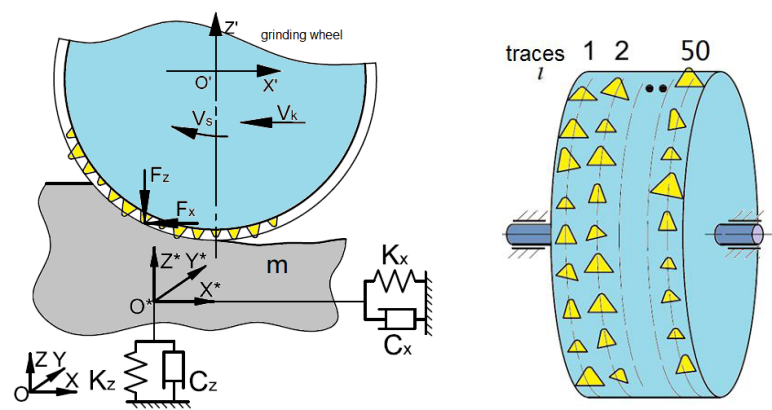

Fig. 1. Dynamical system for simplified grinding model with pliable part, while the wheel is around with grains, having random geometric characteristics

Assume that, the grinding wheel rotates relative to the rigidly fixed axes and makes a feed movement with the speed of $V_{k}$. The cutting forces that occur when cutter enters into the workpiece material we present in the form of components in the feed $(X)$ and normal $(Z)$ direction. Introduce another coordinate system $\mathrm{O}^{*} \mathrm{X}^{*} \mathrm{Y}^{*} \mathrm{Z}^{*}$, located on the workpiece in the contact zone, which moves with the workpiece. The initial data are shown in the Table 1.

Table 1. Basic data for the simplified model of flat grinding.

\begin{tabular}{|c|c|}
\hline $\begin{array}{c}\text { Angular velocity of tool, } \\
\omega\end{array}$ & $150 \mathrm{rad} / \mathrm{s}$ \\
\hline Feed speed, $s$ & $250 \mathrm{~mm} / \mathrm{s}$ \\
\hline $\begin{array}{c}\text { The radius of the } \\
\text { grinding wheel } r_{\mathrm{s}}\end{array}$ & $105 \mathrm{~mm}$ \\
\hline Depth of cut $a_{\mathrm{e}}$ & $0.2 \mathrm{~mm}$ \\
\hline $\begin{array}{c}\text { Width of grinding wheel } \\
b\end{array}$ & $5 \mathrm{~mm}$ \\
\hline $\begin{array}{c}\text { Number of tracks } N^{*} \\
\text { The number of grains in } \\
\text { a track } N\end{array}$ & 5000 \\
\hline $\begin{array}{c}\text { Number of grains in the } \\
\text { contact zone on one } \\
\text { track }\end{array}$ & 49 \\
\hline
\end{tabular}

While the dynamics modelling the detailed information about the distribution of abrasive grains and their stochastic geometric characteristics and the system of equations describing the formation of new surface are the same as presented in paper [5]. For the grinding process modelling taking part's compliance into account, the difference while interpolating the new surface $N(t)$ concludes in the fact that it's necessary to take consideration of the workpiece's dynamic displacement. Thus, in the system of equations, describing the formation of new surfaces, only one equation changes in comparison with the system of equations given in paper [5]:

$$
\Pi(t)=\operatorname{Trend}\left[\left.\Pi_{j}\right|_{t-T / N}-h_{c u, j}(t)+\Delta x \cdot \sin \left(\varphi_{j}(t)\right)+\Delta z \cdot \cos \left(\varphi_{j}(t)\right)\right]
$$


where $T / N$ - the period of the grain path; $\Pi(t)$ - the coordinates of the surface recorded in the information data bank in "Matlab" software; $\Pi_{j \mid t-T / N}$ - the position of the point of intersection between the axis of the $j$-th grain at time $t$, and the surface of the workpiece at time $t-t / N$ in the polar coordinate system; $\Delta \mathrm{x}, \Delta \mathrm{z}$ - projection of dynamic displacement onto the axis $X, Z ; \varphi_{j}(t)$ - the instantaneous angular immersion of the $\mathrm{j}$-th grain of the $i$-th track, which is measured clockwise from the normal axis $(Z)$, when the tool rotates with angular velocity $\omega$.

After determining the cutting thickness $h_{c u, i j}$ of grains in the contact area we apply the relationship between the cutting forces and the area of immertion $A_{h}$ in the form of power functions, which were given in the publication [6], thus the cutting force of each grain in the contact area can be calculated.

\section{The generation of surface under several passes of grinding wheel}

The model describing the surface geometry of the $i$-th track is discrete. Intersection of repetitive cutting occurs with several passes of the grinding wheel. Thus, the treated surface obtained at the previous pass of the circle $N\left(t-T^{*}\right)$ becomes the untreated surface at the present pass of the circle $N(t)$, as shown in Fig. 2. (where, $\mathrm{T}^{*}$ is the time between successive passes of the wheel. In this paper, we assume that $T^{*}=0.01 \mathrm{c}$.

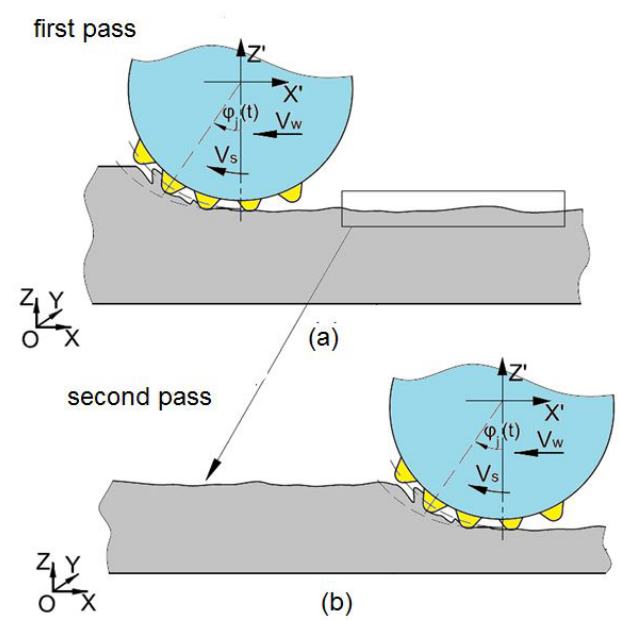

Fig. 2. Scheme of the model of grinding, with the surface under cutting by several passes of the wheel

The following assumptions are introduced: at $\mathrm{t}=0$ the coordinates of the grinding wheel centre in the coordinate system OXYZ are $\left(X_{o^{\prime}}(0), Z_{o^{\prime}}(0)\right)=(200,155.8)[\mathrm{mm}]$. In the case of high stiffness of tool-part elastic system, displacements due to vibration can be neglected. The solution of the system of equations is obtained under the conditions $\Delta x=0, \Delta z=0$. The results without consideration of displacement due to vibration are shown in Fig. 3. The enlarged view of surface formation near the selected zones I and II show us that there are several zones (highlighted with purple circles) where adjacent surfaces intersect. It means that $h_{c u, j}=0$, i.e. the current grain doesn't cut into the part material. 


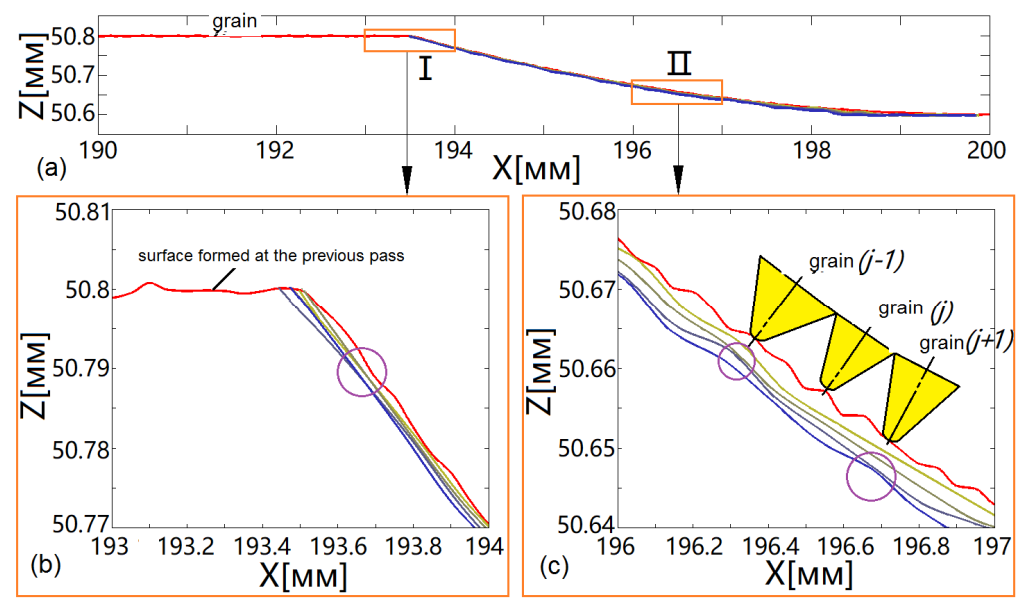

Fig. 3. (a) The surface configuration of the workpiece without consideration of the vibration in the time interval $5 \cdot \mathrm{T} / \mathrm{N}$ under the second pass of the wheel, $(b)$ enlarged view I, $(c)$ enlarged view II

\section{The dynamical system with consideration of vibration}

In this paper we assume that the workpiece is fixed elastically and can vibrate in XOZ plane, while the grinding wheel rotates in rigidly fixed supports. Summing up the cutting forces acting on all grains in contact zone between wheel and workpiece, we obtain the resultant grinding forces acting on the tool $\left(F_{x}, F_{z}\right)$. The system of differential equations describing the workpiece movement has the form [3]:

$$
\left\{\begin{array}{l}
m \cdot \ddot{x}+C_{x} \cdot \dot{x}+K_{x} \cdot x=F_{x} \\
m \cdot \ddot{z}+C_{z} \cdot \dot{z}+K_{z} \cdot z=F_{z}
\end{array}\right.
$$

where, $m$ - workpiece mass $(m=0.5 \mathrm{~kg}) . C_{x}, C_{z}$ - coefficient of damping for workpiece motion in the direction of the axes $X, Z . K_{x}, K_{z}$ - reduced stiffness factor for workpiece fixation in the direction of $X, Z$. The following dimensionless variables and notations as well as in [1] are introduced:

$$
\begin{aligned}
& \xi=\frac{x}{h_{0}}, \eta=\frac{z}{h_{0}}, t=T \cdot \tau, f_{x}=\frac{T}{2 \pi} \sqrt{\frac{K_{x}}{m}}, f_{z}=\frac{T}{2 \pi} \sqrt{\frac{K_{z}}{m}} \\
& \zeta_{x}=\frac{C_{x}}{2 \sqrt{K_{x} \cdot m}}, \zeta_{z}=\frac{C_{z}}{2 \sqrt{K_{z} \cdot m}}, \bar{F}_{x}=\frac{F_{x}}{m \cdot h_{0}}, \bar{F}_{z}=\frac{F_{z}}{m \cdot h_{0}} .
\end{aligned}
$$

The equations of workpiece motion (1) in dimensionless form are as follows:

$$
\left\{\begin{array}{l}
\ddot{\xi}+4 \pi \zeta_{x} f_{x} \dot{\xi}+4 \pi^{2} f_{x}^{2} \xi=\bar{F}_{x} \\
\ddot{\eta}+4 \pi \zeta_{z} f_{z} \dot{\eta}+4 \pi^{2} f_{z}^{2} \eta=\bar{F}_{z}
\end{array}\right.
$$

where, the workpiece natural frequencies: $f_{n x}=\sqrt{K_{x} / m} / 2 \pi$, damping coefficients $f_{n z}=\sqrt{K_{z} / m} / 2 \pi$, are assumed as: $\zeta_{x}=0.05, \zeta_{z}=0.02$. Differential equations (2) are 
numerically integrated under the initial conditions: at $t=0, \xi(0)=0, \dot{\xi}(0)=0, \eta(0)=0$, $\dot{\eta}(0)=0$.

\section{The simulation results of test example}

When processing low-stiffness parts such as turbine blades, the ratio between the stiffness of the tool and the workpiece may have value $K_{x} / K_{z} \approx 3 \div 4$ [7]. Fig. 4-6 show the results of calculations for $K_{x} / K_{z}=4$.
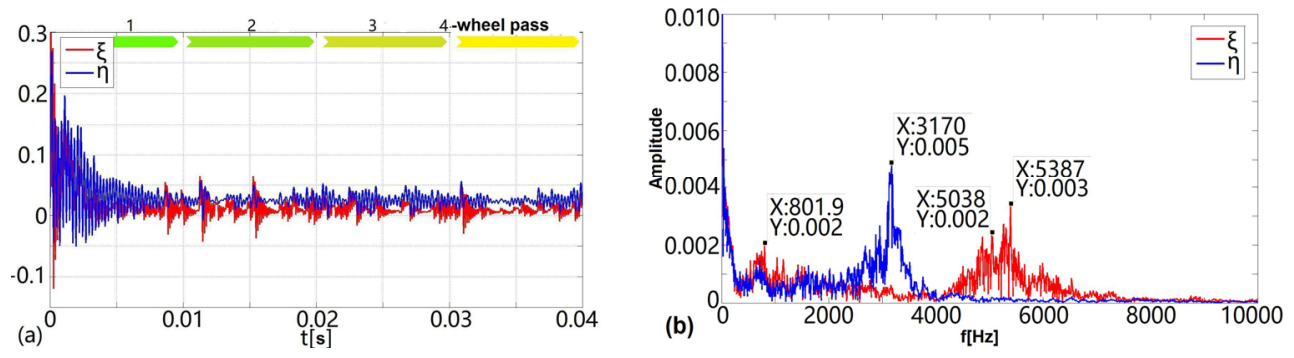

Fig. 4. The dependence of workpiece dimensionless displacements in time $t(a)$, and their spectrum (at time interval $t \geqslant 0.006 \mathrm{~s}$ ) (b) under $K_{x} / K_{z}=4, K_{x}=60 \mathrm{kN} / \mathrm{mm}$

The given results show that, for the case of high values of stiffness $K_{x}\left(K_{x}>45 \mathrm{kN} / \mathrm{mm}\right)$, the system oscillation are damped, the behaviour is stable (see Fig. 4). The Fourier spectra of dimensionless displacements shows that, in this case, the oscillation spectrum of the system is distributed in a wide band of frequencies.

Fig. 5 shows the dependence of workpiece dimensionless displacements in time $t$ and spectra at $K_{x} / K_{z}=4, K_{x}=60 \mathrm{kN} / \mathrm{mm}$. Under such modes, the initial section has region with increasing of the oscillation amplitude, but after a short transient process, the system goes to steady state, which can be also considered satisfactory.
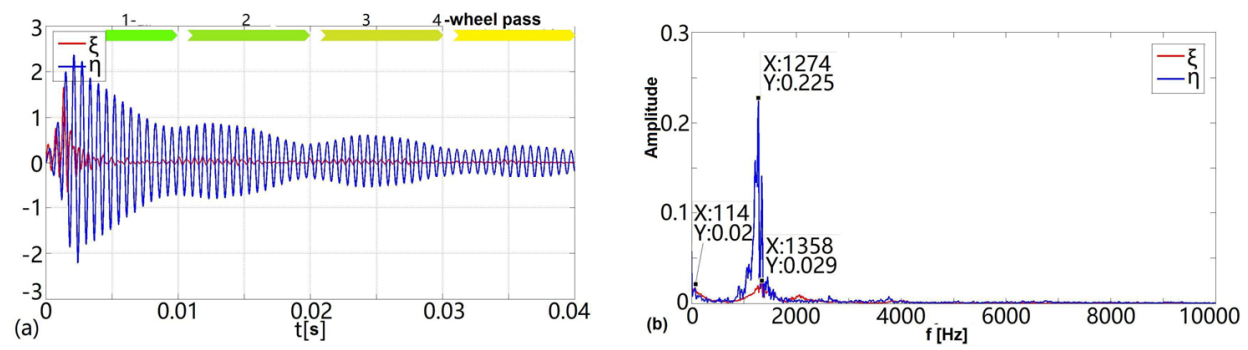

Fig. 5. The dependence of part's dimensionless displacements on time $t(a)$, and their spectrum (on time interval $t \geqslant 0.006 \mathrm{~s})(b)$ at $K_{x} / K_{z}=4, K_{x}=30 \mathrm{kN} / \mathrm{mm}$
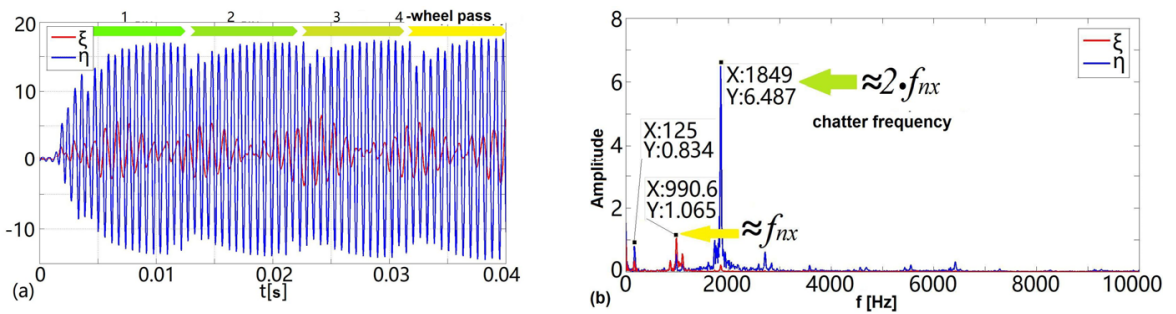

Fig. 6. The dependence of workpiece dimensionless displacements in time $t(a)$, and their spectrum (at time interval $t \geqslant 0.006 \mathrm{~s}$ ) (b) under $K_{x} / K_{z}=4, K_{x}=20 \mathrm{kN} / \mathrm{mm}$ 
And for cases with smaller values of $K_{x}$, there are oscillations with a large amplitude, whose value exceeds the grain size, which indicates the non-operability of such modes (Fig. 6). When reducing the stiffness values $\mathrm{Kx}$, the spectrum has a more discrete character with pronounced peaks at discrete frequencies. To find out the natural oscillations in the peak zones, considering the values of the natural frequencies of system (2), are presented in Table. 2 at different ratios $K_{x} / K_{z}=4$.

Table 2. Natural frequencies of the system at $K_{x} / K_{z}=4$.

\begin{tabular}{|c|c|c|}
\hline$K_{x}(\mathrm{kH} / \mathrm{MM})$ & $f_{n x}\left(\Gamma_{ц}\right)$ & $f_{n z}\left(\Gamma_{ц}\right)$ \\
\hline 20 & 1007 & 503 \\
\hline 30 & 1232 & 616 \\
\hline 60 & 1510 & 755 \\
\hline
\end{tabular}

If analyse the characteristics of the solution by using the method of detection "chatter" described in publications [8-12], we can capture the appearance of "chatter" in the simulation. This behaviour is especially typical for the case when $K_{x} / K_{z}=4, K_{x}=20 \mathrm{kN} / \mathrm{mm}$ (Fig. 6 , in this case $f_{n x}=2 \cdot f_{n z}$ ), for which the frequency of the highest peak is a multiple of 2 to the natural frequency of $f_{n x}$. In this case, the frequency of "chatter" becomes dominant; the system becomes unstable under the dominant frequency of the "chatter". In addition, the offsets in Fig. 5-6 can be obviously divided into 4 zones. Their spectra have explicit peaks at the frequency $f^{*} \approx 1 / T^{*}=100 \mathrm{~Hz}$. This can be explained by the influence of the periodic passes of wheel on dynamic displacement.

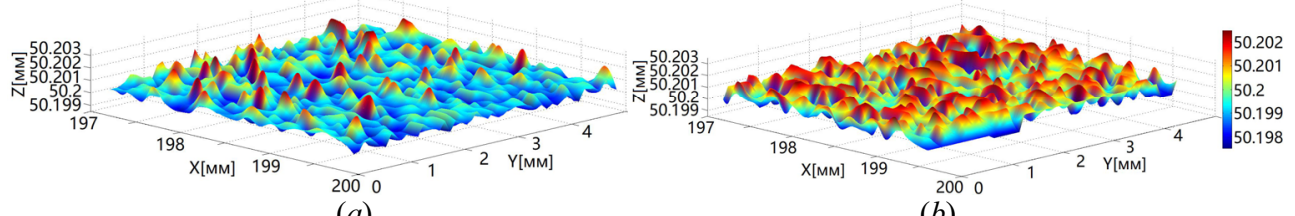

(a)

(b)

Fig. 7. Simulation textures of the treated workpiece surface of without $(a)$ and with $(b)$ consideration of part's vibration at the fourth wheel's pass

In Fig. 7 comparison of treated surface textures without and with consideration of dynamics at the fourth wheel's pass is shown. It can be seen that, on the surface obtained with consideration of dynamics, the number of peaks in the interval becomes greater but their amplitudes decrease.

\section{Conclusions}

The spectral characteristics of dynamic system at different ratios of fixing stiffness of the part $K_{x} / K_{z}$ are investigated. The simulation results show that for stiffness parameters $\left(K_{x}>20\right.$ $\mathrm{kN} / \mathrm{mm}$ ), when the system is stable, displacement amplitude is small, then the grinding process can be considered as milling process with a large number of cutting edges. And for unstable modes $\left(K_{x}<20 \mathrm{kN} / \mathrm{mm}\right)$ the amplitude of dimensionless displacements grows, then it's necessary to consider the model of grinding taking the geometric limit of the grain height, the contribution of the contact of bond with workpiece material into account.

The reported study was funded by RFBR according to the research project № 17-08-01421 \18. 


\section{References}

1. S. A. Voronov, W. Ma, Problemy mashinostroeniya i nadejnosty mashin, 4, 85 (in Russian) (2017)

2. V. N. Kasheev, Abrasivnoe razrushenie tverdykh tel (Nauka publ., Moscow, 1970) (in Russian)

3. I. A. Kiselev, S. A. Voronov, A. A. Shirshov, I. I. Ivanov, Nauka I Obrazovanie. Bauman MSTU. Electronic journal, 10, 47 (in Russian) (2015)

4. I. A. Kiselev, I. S.Voronova, A. A. Shirshov, S. M. Nickolaev, Nauka I Obrazovanie. Bauman MSTU. Electronic journal, 09, 1 (in Russian) (2015)

5. S. A. Voronov, W. Ma, I. S. Voronova, Izvestiya vyshikh uchebnykh zavedeniy. Mashinostroenie, 11, 68 (in Russian) (2017)

6. S. A. Voronov, W. Ma, Vestnik MGTU im. N.E. Baumana. "Mashinostroenie", 5, 52 (in Russian) (2017)

7. E. Budak, L.T. Tunc, S. Alan, CIRP Annals - Manufacturing Technology, 61, 339 (2012)

8. Y. Altintas, Manufacturing Automation: Metal Cutting Mechanics, Machine Tool Vibrations, and CNC Design. (Cambridge University Press, 2000)

9. Y. Altintas, G. Stepan, D. Merdol, Z. Dombovari, CIRP Journal of Manufacturing Science and Technology, 1, 35 (2008)

10. R. O. Anderson, Computer-Aided Design, 10 (2), 231 (1978)

11. C. Brecher, M. Esser, S. Witt, CIRP Annals - Manufacturing Technology, 58, 588 (2009)

12. T. Somkiat, S. Angsumalin, The 4th International Conference on Advances in Mechanics Engineering, 28, 1 (2015) 